\title{
BENTUK DAN PENGGUNAAN BAHASA HALUS DALAM MASYARAKAT MELAYU DAN IBAN DI SARAWAK
}

\author{
Hamidah Abdul Wahab*1 \\ Siti Marina Kamil ${ }^{2}$ \\ Remmy Gedat ${ }^{3}$ \\ 1,2,3 Fakulti Bahasa dan Komunikasi, Universiti Malaysia Sarawak \\ 1awhamidah@unimas.my \\ ${ }^{2}$ ksmarina@unimas.my \\ ${ }^{3}$ gremmy@unimas.my
}

Manuscript received 21 February 2020

Manuscript accepted 16 June 2020

${ }^{*}$ Corresponding author

https://doi.org/10.33736/ils.2103.2020

\begin{abstract}
ABSTRAK
Kajian ini meneliti aspek kesantunan bahasa dalam masyarakat Melayu Sarawak dan Iban di daerah Kuching dan Samarahan, khususnya dalam penggunaan bahasa halus atau eufemisme. Objektif khusus kajian adalah untuk meneliti bentuk eufemisme yang wujud dan digunakan dalam masyarakat Melayu Sarawak dan Iban, dan juga melihat sejauh mana eufemisme tersebut digunakan dalam kedua-dua masyarakat tersebut. Data kajian diperoleh menerusi kaedah soal selidik, melibatkan responden seramai 50 orang bagi setiap kaum. Soalan dirangka mengikut beberapa domain daripada pengkategorian eufemisme oleh Allan dan Burridge (1991), iaitu hal kewanitaan dan kelelakian, kemarahan/makian/kebencian, penyakit, kematian, dan ketakutan berunsurkan haiwan serta makhluk halus. Dapatan kajian menunjukkan penggunaan bahasa halus secara sederhana adalah tinggi, iaitu bagi golongan penutur berusia 40 tahun ke bawah, melibatkan kedua-dua masyarakat. Penutur juga didapati memahami perkataan dan ujaran bahasa halus walaupun ia tidak bersifat langsung. Kajian ini juga dapat memperjelas bentuk bahasa halus yang wujud dan tahap penggunaannya dalam masyarakat Melayu Sarawak dan Iban, selain memaparkan latar budaya masyarakat penutur yang kaya dengan kehalusan bahasanya.
\end{abstract}

Kata kunci: bahasa halus; domain; bahasa sukuan; budaya; Melayu Sarawak; Iban 


\title{
FORMS AND USAGE OF EUPHEMISM AMONG THE MALAY AND IBAN COMMUNITIES IN SARAWAK
}

\begin{abstract}
This study examines the aspect of politeness in the language used by the Sarawak Malays and Ibans residing in Kuching and Samarahan in Sarawak, specifically the uses of euphemism. The objectives of this study are to identify the forms of euphemism that exist and are used by the Malay and Iban speakers, and to investigate the extent of usage. The research data were obtained from questionnaires distributed to 50 respondents from each ethnic group. The questionnaire was adapted from Allan and Burridge's (1991) selected domain of euphemism categorisation which includes domains on male and female, emotion, illness, death and fear of animals, and the supernatural. The results showed that the group below 40 years old among both the Sarawak Malay and Iban speakers mostly used a moderate amount of euphemisms. They could understand euphemisms that were indirect. This study has identified the forms of emphemisms and the extent of euphemism usage in both speech communities, as well as shown the richness of the cultural background of the Sarawak Malay and Iban languages.
\end{abstract}

Keywords: euphemism; domain; indigenous language; culture; Sarawak Malay; Iban

\section{Pengenalan}

Bahasa halus atau eufemisme, seperti dinyatakan Asmah Haji Omar (2008) merujuk kepada bentuk kiasan yang menggambarkan sesuatu rujukan dengan cara memberi kesan yang baik, iaitu apabila benda yang dirujuk tersebut mengandungi makna yang buruk, kasar dan seumpamanya. Tujuan penggunaan bahasa halus adalah untuk melembutkan kekasaran bahasa, di samping berfungsi sebagai strategi sopan untuk menjaga hati dan perasaan orang yang mendengar. Bahasa yang bersifat halus ini lazim digunakan sebagai satu cara berbahasa oleh penutur bagi menjaga perasaan pendengar yang berada dalam emosi sedih seperti kematian ahli keluarga, menutup keaiban orang yang dicakapkan, mengelakkan daripada berlaku kasar atau menyinggung perasaan pendengar, meminimumkan ketegangan, dan seumpamanya.

Penyelidikan ini dijalankan untuk meneroka aspek kesantunan dalam berbahasa, melibatkan eufemisme dalam bahasa yang digunakan oleh dua suku kaum terbesar di Sarawak, iaitu Melayu dan Iban. Kajian kebahasaan melibatkan bahasa sukuan kaum ini dilihat wajar dijalankan kerana kepentingannya sebagai bahasa utama di Sarawak, yang berperanan sebagai bahasa perhubungan atau lingua franca di Sarawak (Mohammed Azlan Mis, 2010, 2012). Kupasan aspek bahasa halus dalam kedua-dua masyarakat juga dilihat signifikan untuk menunjukkan bahawa wujudnya kata-kata dan ungkapan yang lembut, halus dan 
sopan sifatnya, untuk menggantikan kata-kata atau ungkapan yang dianggap kasar atau dilarang dituturkan secara terang-terangan dalam interaksi seharian.

Menerusi kajian ini, bentuk bahasa halus yang digunakan dalam masyarakat Melayu Sarawak dan Iban dijelaskan berdasarkan domain-domain tertentu seperti hal kewanitaan dan kelelakian, kemarahan/makian/kebencian, penyakit, kematian, dan ketakutan berunsurkan haiwan serta makhluk halus. Tahap penggunaan bahasa halus dalam konteks seharian bagi kedua-dua masyarakat turut dipaparkan, iaitu untuk melihat sama ada penggunaan bahasa halus adalah signifikan dalam kalangan penutur kajian, atau sebaliknya.

\section{Kajian Lepas}

Eufemisme atau bahasa halus dikaji oleh penyelidik luar dan dalam negara, dengan pelbagai pendekatan, skop dan teori. Hal ini disebabkan oleh wujudnya topik-topik yang bersifat rentas budaya, seperti kematian, penyakit, anggota tubuh badan tertentu, fungsi anggota badan tertentu, dan seumpamanya didapati dalam kebanyakan masyarakat di dunia. Sungguhpun topik-topik ini dapat dianggap sejagat (Rabab'ah \& Al-Qarni, 2012), namun begitu cara ucapan dan penggunaannya adalah berbeza-beza, berdasarkan kelaziman dan norma budaya penutur sesebuah masyarakat yang menggunakannya. Penggunaan bahasa halus adalah lazim untuk menunjukkan timbang rasa kepada pendengar, di samping berlaku sopan dalam perbualan dan mengelakkan rasa kurang senang terhadap sesuatu topik atau isu yang berupaya menimbulkan ketakutan, keaiban dan kejijikan.

Jamet (2018) misalnya meneliti fungsi neologikal eufemisme berkaitan penyakit dalam bahasa Inggeris dan Perancis. Kajian yang berfokus untuk menilai peranan utama dan fungsi tabu dan bahasa tabu dengan berpandukan kerangka Allan dan Burridge (1991) ini memanfaatkan data yang diperoleh daripada pelbagai sumber termasuk blog, laman web, pertuturan seharian, kamus dan korpus seperti Corpus of Contemporary American English dan Sketch Engine. Dapatan kajian menunjukkan eufemisme mempunyai keunikan dalam melembutkan ujaran berkenaan perkara sensitif seperti penyakit. Penggunaan bahasa ini juga dinyatakan boleh diganti sebagaimana penyakit baru yang muncul dalam kehidupan manusia. Penggantian ini menunjukkan penggunaan sesuatu bahasa bersifat dinamik dan berubah mengikut senario semasa.

Kajian Rabab'ah dan Al-Qarni (2012) pula melihat strategi penggunaan eufemisme dalam bahasa Arab dan Inggeris Britain. Data diperoleh melalui soal selidik yang diedarkan kepada 300 orang pelajar kolej di Arab dan England. Kajian ini melibatkan 150 orang responden dari King Saud University dan 150 orang responden lagi dari University of Hull. Pembahagian gender adalah sama rata, iaitu 75 pelajar lelaki dan 75 pelajar perempuan untuk setiap universiti. Item soal selidik kajian memfokus kepada tiga topik tabu, iaitu kematian, pembohongan dan fungsi anggota tubuh. Dapatan kajian mendapati bahasa Arab mempunyai cara yang lebih banyak untuk mengujarkan eufemisme dan tiada hubungan signifikan yang mengkaitkan pemilihan strategi eufemisme dengan gender. Kedua-dua komuniti turut menunjukkan bahawa penggunaan eufemisme dipengaruhi oleh kepercayaan agama pengguna bahasa, di samping norma dan gaya hidup mereka. 
Dalam konteks Malaysia, kajian bahasa halus melibatkan masyarakat Melayu telah dijalankan oleh beberapa pengkaji, antaranya termasuklah Noriah Mohamed dan Jamilah Bebe Mohamad (2016). Secara khusus, kajian tersebut membincangkan tabu dan eufemisme kematian dalam salah satu subdialek dalam dialek Melayu Kedah, yang dinamakan sebagai dialek Melayu Kedah Sungai Petani. Aspek yang diteliti ialah persamaan dan perbezaan tabu dan eufemisme dalam dialek tersebut berbanding dengan Bahasa Melayu standard. Antara dapatan kajian yang ditonjolkan adalah untuk menyatakan kematian dalam dialek tersebut, seperti ungkapan "meninggai", "dah sampai masa", "pi", "sampai hukum", "dah tak dak", dan "habeh umoq". Ungkapan lain yang digunakan untuk memperkatakan hal-hal kematian yang merujuk "kubur" adalah seperti "enam kaki dalam", "batu dua" dan "rumah kekai". Penggunaan ungkapan ini bertujuan memaniskan ungkapan "kubur", di samping untuk keselesaan kepada pihak yang mendengar. Dapatan kajian tersebut juga menunjukkan wujudnya persamaan dan perbezaan eufemisme dalam dialek yang dikaji dengan Bahasa Melayu standard.

Kajian bahasa halus yang memfokus kepada masyarakat di Sarawak pula dijalankan oleh Affidah Morni, Aiza Johari, Johny Ahmad dan Kamaruzaman Jusoff (2009). Kajian tersebut membandingkan penggunaan tabu dan bahasa halus dalam masyarakat Melayu dan Iban, dengan mengetengahkan topik seks, anggota badan tertentu dan fungsinya, dan hal kematian. Menerusi kajian Affidah Morni et al., didapati bahawa pengujaran melibatkan hal-hal tabu tidak dilakukan secara langsung, sebaliknya penutur menggunakan eufemisme untuk tujuan kesopanan. Berbanding dengan penutur Melayu, penutur Iban didapati lebih berterus terang dalam penggunaan kata-kata berkaitan hal tabu, khususnya untuk mengungkapkan perasaan dan emosi mereka. Penggunaan tabu dalam masyarakat kajian juga dipengaruhi oleh norma budaya, peraturan, kesopanan, dan agama.

Selain kajian Affidah Morni et al. (2009), kajian yang dijalankan oleh Hamidah Abdul Wahab, Imran Ho Abdullah, Mohammed Azlan Mis, dan Khazriyati Salehuddin (2016) didapati memfokus kepada eufemisme kematian. Kaedah lapangan digunakan untuk memperoleh data, melibatkan informan di daerah Kuching, Sarawak. Data kajian seterusnya dianalisis menggunakan kerangka teori Metafora Konsepsi. Dapatan kajian menunjukkan bahawa pengkonsepsian eufemisme kematian seperti "pegi, meninggal dunia, pulang ke rahmatullah, dan kembali ke rahmatullah" dalam masyarakat Melayu Sarawak didasari oleh skema imej Sumber-Laluan-Matlamat, di samping metafora konsepsi "kematian itu lokasi yang lebih baik, kehidupan itu perjalanan, dan kematian itu pelepasan" dan "Kematian itu perjalanan". Budaya Melayu dan agama Islam didapati kuat mempengaruhi pengkonsepsian eufemisme kematian dalam masyarakat Melayu Sarawak.

Kajian bahasa halus dalam masyarakat Iban pula dijalankan oleh Harishon dan David (2012). Kedua-dua pengkaji meneliti eufemisme dan perumpamaan dalam cerita hikayat Iban, iaitu untuk menonjolkan unsur kesantunan yang wujud dalam wacana tersebut. Menerusi penggunaan data daripada teks hikayat Iban dan kajian lapangan, hasil kajian menunjukkan bahawa tabu dan eufemisme yang digunakan menjurus kepada aspek kematian, kehamilan, kanak-kanak, dan perlakuan makan, di samping dalam upacara doa sebagai tanda hormat kepada Tuhan untuk memohon 
keberkatan dan kesejahteraan. Terdapat juga eufemisme masyarakat Iban pada zaman dahulu dahulu yang tidak lagi digunakan, selain wujud perubahan pada bentuk eufemisme pada zaman sekarang, kesan daripada perubahan sistem kepercayaan dan amalan hidup masyarakat.

Selain itu, kajian bahasa halus dalam masyarakat Iban dijalankan oleh Ringit, Hamidah Abdul Wahab dan Gedat (2019). Dengan memfokus kepada domain kepercayaan, kajian tersebut memperoleh data menerusi kajian lapangan di perkampungan masyarakat Iban Sebuyau dan seterusnya membuat analisis berdasarkan kerangka semantik kognitif, iaitu metafora konsepsi. Antara ungkapan bersifat halus yang diketengahkan termasuklah enda' lantang (tidak selesa), yang merujuk kepada kepercayaan berkaitan petanda baik atau buruk dalam mimpi, dan pansa' utai (dilintasi oleh sesuatu), yang berkait dengan kepercayaan perihal gangguan roh jahat terhadap seseorang. Daripada analisis, ungkapan enda' lantang didasari oleh metafora konsepsi "mimpi jai' itu enda' lantang" (mimpi buruk itu tidak selesa), (mimpi adalah entity perasaan), manakala "pansa' utai" didasari oleh "kachau antu adalah pansa" utai" (gangguan roh jahat itu dilintasi oleh sesuatu), "hantu itu symbol kejahatan). Dapatan kajian secara keseluruhan menunjukkan bahawa bahasa halus dalam domain kepercayaan masyarakat ini dipengaruhi oleh pengetahuan dan pengalaman persekitaran penutur yang berkait rapat dengan adat resam, amalan dan pemerhatian terhadap alam sekelilingnya.

Kajian-kajian yang diketengahkan ini mengupas aspek bahasa halus dalam konsep budaya dan masyarakat, sejajar dengan objektif dan lingkungan penulisan mereka. Namun begitu, kajian yang menjelaskan bentuk dan jenis bahasa halus, dan tahap penggunaan bahasa ini dalam masyarakat Melayu Sarawak dan Iban didapati masih kurang dijalankan. Maka, penyelidikan yang dijalankan ini akan meneliti aspek-aspek yang dinyatakan dan menjelaskan senario penggunaan bahasa halus dalam kedua-dua masyarakat.

\section{Kaedah Kajian}

Kajian ini melibatkan kaedah soal selidik dan temu bual yang dijalankan di daerah Kuching dan Samarahan, Sarawak. Untuk memperoleh data bahasa halus, soal selidik dirangka dengan mengambil beberapa domain daripada pengkategorian eufemisme oleh Allan dan Burridge (1991), iaitu hal kewanitaan dan kelelakian; kemarahan/makian; kebencian; penyakit; kematian; dan ketakutan berunsurkan haiwan serta makhluk halus. Penggunaan eufemisme yang dikelaskan dalam pengkategorian ini meliputi perkataan dan ungkapan yang tidak diucapkan secara langsung bagi merujuk sesuatu topik atau perkara yang diperkatakan, khususnya yang dilihat mempunyai metafora atau kiasan. Contohnya perkataan "kembali" yang digunakan dalam masyarakat Melayu Sarawak dan "udah nadai" (sudah tiada) dalam masyarakat Iban merujuk kepada kematian seseorang. Menerusi contoh ini, dapat dilihat unsur bahasa tidak langsung dan berkias terhadap ketiadaan seseorang yang bukan merujuk kepada pemergiannya ke sesuatu tempat, sebaliknya kerana meninggal dunia dan tiada lagi secara fizikal di dunia.

Bagi memenuhi objektif kajian yang kedua, temu bual yang dijalankan berlandaskan beberapa persoalan utama yang dapat mencerminkan penggunaan 
bahasa halus secara lebih mendalam dalam kalangan masyarakat Melayu dan Iban. Aspek yang ditimbulkan merangkumi tahap penggunaan bahasa halus dalam pertuturan seharian, iaitu secara kerap atau sebaliknya. Senario penggunaan bahasa halus dalam interaksi juga diteliti, termasuklah dari segi kefahaman penutur dalam penggunaan bahasa halus yang lazimnya bersifat tidak langsung, keselesaan penggunaan bahasa halus daripada bahasa biasa atau kasar, dan penggunaan bahasa halus sebagai strategi kesopanan. Di samping itu, temu bual turut mendapatkan data dari fungsi bahasa halus yang dapat menggambarkan budaya berbahasa dan identiti masyarakat, serta sejauh mana penggunaan bahasa ini dalam merapatkan hubungan antara penutur.

Responden kajian terdiri daripada 50 orang penutur Melayu Sarawak dan 50 orang penutur bahasa Iban, meliputi jantina lelaki dan wanita. Pengelasan responden kajian dibuat dengan dua kategori umur, iaitu masing-masing 25 orang responden berusia 40 tahun ke bawah dan 25 orang responden berusia 40 tahun ke atas. Responden dengan kategori umur berbeza dipilih untuk meneliti sama ada terdapat juga perbezaan dari segi tahap dan penggunaan bahasa halus dalam angkubah umur ini. Kesemua responden merupakan penduduk asal kawasan Kuching dan Samarahan, berketurunan Melayu dan Iban.

\section{Dapatan dan Perbincangan}

Perbincangan dan dapatan dalam bahagian ini difokuskan kepada bentuk bahasa halus dan tahap penggunaan bahasa halus dalam masyarakat Melayu Sarawak dan Iban. Dibincangkan juga senario dan fungsi penggunaan bahasa halus dalam keduadua masyarakat.

\section{Bentuk Bahasa Halus Masyarakat Melayu Sarawak dan Iban}

Kajian ini bertujuan untuk memaparkan bentuk bahasa halus masyarakat Melayu Sarawak dan Iban. Penggolongan data bahasa halus dibuat mengikut pengkategorian eufemisme oleh Allan dan Burridge (1991). Jadual 1 menunjukkan bahasa halus dalam masyarakat Melayu Sarawak, manakala Jadual 2 merupakan data bahasa halus masyarakat Iban.

Jadual 1

Data bahasa halus masyarakat Melayu Sarawak

\begin{tabular}{|l|l|l|l|}
\hline Kategori & $\begin{array}{l}\text { Bahasa biasa/ } \\
\text { bahasa kasar }\end{array}$ & Bahasa halus & Makna \\
\hline $\begin{array}{l}\text { 1. Hal } \\
\text { kewanitaan/ } \\
\text { kelelakian }\end{array}$ & Haid & $\begin{array}{c}\text { datang kain, datang bulan, } \\
\text { datang kotor } \\
\text { sik dapat beranak, sikpat buntin, } \\
\text { sik subo, sikda rezeki anak } \\
\text { sik dapat bediri, sikpat bangun, } \\
\text { sik angkat, sik hidup, lemah } \\
\text { batin, patah, mati } \\
\text { mati pucok }\end{array}$ & haid \\
& buntin & mati pucuk & hamil \\
\hline
\end{tabular}




\begin{tabular}{|c|c|c|c|}
\hline & $\begin{array}{l}\text { buntin anak } \\
\text { ampang, } \\
\text { buntin luar } \\
\text { nikah } \\
\text { becerei } \\
\\
\text { mencereikan } \\
\text { bekendak }\end{array}$ & $\begin{array}{l}\text { buntin luar nikah, buntin awal, } \\
\text { buntin dolok, ada oleh, } \\
\text { telanjur } \\
\text { bepisah, putus, sikda jodoh, sik } \\
\text { diam sama, sik sama agi, } \\
\text { jodoh sik panjang, tak } \\
\text { serumah, jodoh sik panjang } \\
\text { melepas } \\
\text { main belakang, main kayu tiga, } \\
\text { sik cukup sorang, ada } \\
\text { simpanan }\end{array}$ & $\begin{array}{l}\text { hamil tanpa } \\
\text { nikah } \\
\text { bercerai } \\
\text { menceraikan } \\
\text { curang }\end{array}$ \\
\hline $\begin{array}{l}\text { 2. Kemarahan/ } \\
\text { makian } \\
\text { (berkaitan } \\
\text { kebodohan, } \\
\text { kelemahan, } \\
\text { kekurangan } \\
\text { orang) dan } \\
\text { kebencian } \\
\text { (berkaitan } \\
\text { perangai buruk } \\
\text { orang) }\end{array}$ & $\begin{array}{l}\text { bodoh } \\
\text { entingal } \\
\text { pemalas } \\
\text { gambong } \\
\text { gemok } \\
\text { miskin } \\
\text { pondan } \\
\text { tomboi } \\
\text { anak luar nikah } \\
\text { pelacur }\end{array}$ & $\begin{array}{l}\text { bengap } \\
\text { sik dengar kata } \\
\text { berat tulang } \\
\text { ngegeh } \\
\text { berisik, sihat } \\
\text { makan kesian } \\
\text { suntun (sotong), maknyah, } \\
\quad \text { lembut, jadi laki, abang } \\
\text { songsang } \\
\text { anak terlanjur } \\
\text { kupu-kupu malam, perempuan } \\
\quad \text { lorong }\end{array}$ & $\begin{array}{l}\text { bodoh } \\
\text { degil } \\
\text { malas/pemalas } \\
\text { engada-ngada } \\
\text { gemuk } \\
\text { iskin } \\
\text { pondan } \\
\text { tomboi } \\
\text { anak luar nikah } \\
\text { pelacur }\end{array}$ \\
\hline $\begin{array}{l}\text { 3. Ketakutan } \\
\text { berunsurkan } \\
\text { haiwan serta } \\
\text { makhluk halus }\end{array}$ & $\begin{array}{l}\text { antu } \\
\text { tempat berisik } \\
\text { boyak } \\
\text { rimo }\end{array}$ & $\begin{array}{l}\text { semandin } \\
\text { tempat keras, ngutik } \\
\text { bujang senang, semandin } \\
\text { ak belang }\end{array}$ & $\begin{array}{l}\text { hantu } \\
\text { tempat berhantu } \\
\text { buaya } \\
\text { harimau }\end{array}$ \\
\hline 4. Penyakit & $\begin{array}{l}\text { gila } \\
\text { arah }\end{array}$ & $\begin{array}{l}\text { sik betul, sot, sik siuman, ilang } \\
\text { akal, sik berapa gilak } \\
\text { ada penyakit, sakit }\end{array}$ & $\begin{array}{l}\text { gila } \\
\text { barah/kanser }\end{array}$ \\
\hline 5. Kematian & $\begin{array}{l}\text { mati } \\
\text { si mati } \\
\text { ngubor, kubor } \\
\text { mayat }\end{array}$ & $\begin{array}{l}\text { ninggal, kembali, kembali ke } \\
\quad \text { rahmatullah } \\
\text { urang ninggal, arwah } \\
\text { disemadi } \\
\text { jenazah }\end{array}$ & $\begin{array}{l}\text { mati } \\
\text { si mati } \\
\text { kebumi } \\
\text { mayat }\end{array}$ \\
\hline
\end{tabular}

Jadual 2

Data bahasa halus masyarakat Iban

\begin{tabular}{|l|l|l|l|}
\hline Kategori & $\begin{array}{l}\text { Bahasa biasa/ } \\
\text { bahasa kasar }\end{array}$ & Bahasa halus & Makna \\
\hline $\begin{array}{l}\text { 1. Hal } \\
\begin{array}{l}\text { kewanitaan/ } \\
\text { kelelakian }\end{array}\end{array}$ & datai indu & $\begin{array}{l}\text { datai kutur, datai kain, datai } \\
\text { bulan } \\
\text { nadai anak, nadai mujur, punas }\end{array}$ & haid \\
mandul
\end{tabular}




\begin{tabular}{|c|c|c|c|}
\hline & $\begin{array}{l}\text { mati pucuk } \\
\text { ngandung } \\
\text { ngampang } \\
\text { sarak } \\
\text { nipu, beduan }\end{array}$ & $\begin{array}{l}\text { nadai purih (lelaki) } \\
\text { betubuh bisi, bisi tubuh } \\
\text { betubuh nadai laki, nengali } \\
\text { nadai begulai agi, enda begulai } \\
\text { butang }\end{array}$ & $\begin{array}{l}\text { mati pucuk } \\
\text { hamil } \\
\text { hamil tanpa } \\
\quad \text { nikah } \\
\text { bercerai } \\
\text { curang }\end{array}$ \\
\hline $\begin{array}{l}\text { 2. Kemarahan/ } \\
\text { makian } \\
\text { (berkaitan } \\
\text { kebodohan, } \\
\text { kelemahan, } \\
\text { kekurangan } \\
\text { orang) dan } \\
\text { kebencian } \\
\text { (berkaitan } \\
\text { perangai buruk } \\
\text { orang) } \\
\end{array}$ & $\begin{array}{l}\text { tambap, tuyu, } \\
\quad \text { palui } \\
\text { manchal } \\
\text { pemalas, } \\
\quad \text { kelalah } \\
\text { kurang ajar } \\
\text { kediri } \\
\text { gemu' } \\
\text { mesekin } \\
\text { anak ampang }\end{array}$ & $\begin{array}{l}\text { nadai nemu utai, nadai nemu } \\
\text { nadai mereti, enda ninga jaku } \\
\text { enggai bekerja, berat tulang } \\
\text { nadai basa } \\
\text { minta puji } \\
\text { pait } \\
\text { idup seranta, adai reta, merinsa } \\
\text { anak nadai apai, anak nengali }\end{array}$ & $\begin{array}{l}\text { bodoh } \\
\text { degil } \\
\text { malas/pemalas } \\
\text { biadap } \\
\text { mengada-ngada } \\
\text { gemuk } \\
\text { miskin } \\
\text { anak luar nikah }\end{array}$ \\
\hline $\begin{array}{l}\text { 3. Ketakutan } \\
\text { berunsurkan } \\
\text { haiwan serta } \\
\text { makhluk halus }\end{array}$ & $\begin{array}{l}\text { antu } \\
\text { berantu } \\
\text { jagu } \\
\text { ular } \\
\text { jami' } \\
\text { kera } \\
\text { nanam padi } \\
\text { ngasu/nimbak } \\
\text { nginti/nyala }\end{array}$ & $\begin{array}{l}\text { mata utai } \\
\text { alai angat, bisi utai, angat palan } \\
\text { jelu ai', raja ai', aki' } \\
\text { akar, tukang belit } \\
\text { jelu sungkur } \\
\text { jelu jangkit } \\
\text { atah } \\
\text { bejalai senapang, mai senapang } \\
\text { bejalai ke ai', berikan, ngabas } \\
\quad \text { sungai }\end{array}$ & $\begin{array}{l}\text { hantu } \\
\text { tempat berhantu } \\
\text { buaya } \\
\text { ular } \\
\text { babi hutan } \\
\text { kera } \\
\text { menanam padi } \\
\text { memburu } \\
\text { memancing }\end{array}$ \\
\hline 4. Penyakit & $\begin{array}{l}\text { gila } \\
\text { kanser }\end{array}$ & $\begin{array}{l}\text { nadai cun, enda betul, sinting } \\
\text { riman }\end{array}$ & $\begin{array}{l}\text { gila } \\
\text { barah/kanser }\end{array}$ \\
\hline 5. Kematian & $\begin{array}{l}\text { parai } \\
\text { pemati, orang } \\
\quad \text { parai } \\
\text { ngubor, kubor } \\
\text { antu, mayat }\end{array}$ & $\begin{array}{l}\text { udah nadai } \\
\text { niang, orang ti nadai } \\
\text { ngubor niang, nganjung niang } \\
\text { niang }\end{array}$ & $\begin{array}{l}\text { sudah tiada } \\
\quad \text { (mati) } \\
\text { si mati } \\
\text { kebumi } \\
\text { mayat }\end{array}$ \\
\hline
\end{tabular}

Data bahasa halus yang diperoleh bagi kedua-dua masyarakat menunjukkan penggunaan berdasarkan kategori dan konteks, meliputi beberapa keadaan seperti untuk tujuan kesopanan apabila berbual dengan orang yang lebih tua, menyelindungkan keaiban dan menghormati orang yang dibualkan, dan untuk memberi nasihat tertentu berkenaan hal-hal kehidupan. Selain itu, penggunaan bahasa halus berkait rapat dengan budaya masyarakat yang dilihat mendidik anakanak berbahasa sopan, agar golongan kanak-kanak tidak mengikut bahasa yang kasar. Adab berbahasa juga diamalkan ketika berada di hutan, kebun dan sungai, yang dipercayai mempunyai entiti ghaib, yang mempunyai kuasa dan semangat yang 
perlu dijaga supaya tidak ditimpa musibah kerana kekasaran dan keterlanjuran berbahasa. Dalam hal ini, dipercayai bahawa sekiranya penutur menggunakan bahasa yang kasar atau tidak sopan, semangat sesuatu entiti yang wujud di hutan, kebun dan sungai akan marah dan menyebabkan individu yang mencari rezeki berkemungkinan tidak mendapat sebarang hasil, malah ditakuti boleh ditimpa bala bencana.

Penelitian data bahasa halus daripada kedua-dua masyarakat yang dikaji turut menunjukkan bahawa topik atau domain yang diketengahkan bersifat sejagat, yang juga mendapat perhatian penyelidik lepas. Penggunaan bahasa halus dalam domain penyakit misalnya telah disentuh oleh Jamet (2018), manakala topik kehamilan dibincangkan juga oleh Harishon dan David (2012). Huraian penggunaan bahasa halus dalam domain kematian didapati turut dikupas oleh Rabab'ah dan AlQarni (2012), Noriah Mohamed dan Jamilah Bebe Mohamad (2016), dan Affidah Morni et al. (2009). Kecenderungan para pengkaji dalam membincangkan penggunaan bahasa halus dalam domain kematian contohnya memperlihatkan bentuk bahasa yang lazim digunakan dalam topik yang sensitif ini, iaitu bahasa yang lahir daripada pengetahuan dan pengalaman penutur, hasil daripada kepekaan dan kesesuaiannya dengan budaya santun masyarakat.

\section{Tahap Penggunaan Bahasa Halus dalam Kalangan Masyarakat Melayu Sarawak dan Iban}

Analisis tahap penggunaan bahasa halus dalam masyarakat Melayu Sarawak dapat ditunjukkan melalui Jadual 3, manakala tahap penggunaan bahasa halus bagi masyarakat Iban dipaparkan menerusi Jadual 4.

Jadual 3

Penggunaan Bahasa Halus dalam Komunikasi Seharian Oleh Penutur Melayu Sarawak

\begin{tabular}{lcccccc}
\hline Umur & $\begin{array}{c}\text { Sangat } \\
\text { kerap }\end{array}$ & Kerap & Sederhana & Kurang & $\begin{array}{c}\text { Sangat } \\
\text { kurang }\end{array}$ & $\begin{array}{c}\text { Jumlah } \\
\text { keseluruhan }\end{array}$ \\
\hline 40 tahun & 2 & 7 & 11 & 5 & 0 & 25 \\
ke atas & $8 \%$ & $28 \%$ & $44 \%$ & $20 \%$ & $0 \%$ & $100 \%$ \\
\hline 40 tahun & 0 & 19 & 3 & 2 & 1 & 25 \\
ke bawah & $0 \%$ & $76 \%$ & $12 \%$ & $8 \%$ & $4 \%$ & $100 \%$ \\
\hline
\end{tabular}

Jadual 4

Penggunaan Bahasa Halus dalam Komunikasi Seharian oleh Penutur Iban

\begin{tabular}{lcccccc}
\hline Umur & $\begin{array}{c}\text { Sangat } \\
\text { kerap }\end{array}$ & Kerap & Sederhana & Kurang & $\begin{array}{c}\text { Sangat } \\
\text { kurang }\end{array}$ & $\begin{array}{c}\text { Jumlah } \\
\text { keseluruhan }\end{array}$ \\
\hline 40 tahun & 0 & 4 & 18 & 1 & 2 & 25 \\
ke atas & $0 \%$ & $16 \%$ & $72 \%$ & $4 \%$ & $8 \%$ & $100 \%$ \\
\hline 40 tahun & 0 & 2 & 19 & 3 & 1 & 25 \\
ke bawah & $0 \%$ & $8 \%$ & $76 \%$ & $12 \%$ & $4 \%$ & $100 \%$ \\
\hline
\end{tabular}


Data dalam Jadual 3 dan 4 menunjukkan penggunaan bahasa halus yang berbeza-beza tahapnya mengikut kaum dan umur, namun cenderung kepada klasifikasi kerap dan sederhana. Misalnya golongan berusia 40 tahun ke bawah bagi masyarakat Melayu Sarawak dan Iban menunjukkan penggunaan bahasa halus secara sederhana ialah paling tinggi iaitu sebanyak $76 \%$. Penggunaan ini didorong oleh sifat bahasa halus yang lebih sopan dan sesuai digunakan untuk menjaga hati dan perasaan pendengar, selain menuruti nasihat orang yang lebih tua agar berbahasa sopan apabila berdepan dengan hal-hal yang berkait dengan kepercayaan; ketakutan berunsurkan haiwan dan makhluk halus.

Bagi golongan berusia 40 tahun ke atas pula, data menunjukkan penggunaan bahasa halus yang dalam kategori kerap adalah lebih menonjol. Hal ini disebabkan kebiasaan penggunaan bahasa halus tersebut dalam kehidupan seharian. Seterusnya kebiasaan ini didorong oleh keinginan golongan ini menunjukkan teladan kepada pihak yang dilawan berbicara, di samping melestarikan pengunaan bahasa yang sesuai dan lembut ketika berkomunikasi, sesuai dengan topik yang diperkatakan dan konteks keperluannya. Penutur yang berusia 40 tahun ke atas bagi kedua-dua kaum juga secara keseluruhannya menampakkan kekerapan pengunaan bahasa halus yang lebih tinggi berbanding golongan muda. Hal ini disebabkan oleh kelaziman untuk berkomunikasi secara berlapik khususnya apabila membicarakan tentang kematian, hal-hal kewanitaan dan kelelakian serta hal berkaitan semangat dan kepercayaan.

\section{Senario Penggunaan Bahasa Halus dalam Kalangan Masyarakat Melayu Sarawak dan Iban}

Senario penggunaan bahasa halus dalam kedua-dua masyarakat dapat diteliti menerusi Jadual 5 dan 6 . Antara aspek yang diketengahkan dalam konteks ini ialah kefahaman terhadap bahasa halus, keselesaan penggunaan bahasa ini dalam komunikasi dan tujuan penggunaannya.

Jadual 5

Senario Penggunaan Bahasa Halus dalam Masyarakat Melayu Sarawak

\begin{tabular}{lcccc}
\hline & \multicolumn{2}{c}{$\begin{array}{c}\text { Umur } \mathbf{4 0} \text { tahun } \\
\text { ke atas }\end{array}$} & \multicolumn{2}{c}{$\begin{array}{c}\text { Umur } \mathbf{4 0} \text { tahun } \\
\text { ke bawah }\end{array}$} \\
\cline { 2 - 5 } & Ya & Tidak & Ya & Tidak \\
\hline Mudah memahami bahasa halus walaupun & 19 & 6 & 22 & 3 \\
tidak menggunakan bahasa yang berterus & $76 \%$ & $24 \%$ & $88 \%$ & $12 \%$ \\
terang & & & & \\
\hline Selesa menggunakan bahasa halus daripada & 18 & 7 & 22 & 3 \\
bahasa biasa/ bahasa kasar & $72 \%$ & $28 \%$ & $88 \%$ & $12 \%$ \\
\hline Menggunakan bahasa halus sebagai cara & 25 & 0 & 24 & 1 \\
menunjukkan kesopanan & $100 \%$ & 0 & $96 \%$ & $4 \%$ \\
\hline
\end{tabular}


Jadual 6

Senario Penggunaan Bahasa Halus dalam Masyarakat Iban

\begin{tabular}{|c|c|c|c|c|}
\hline & \multicolumn{2}{|c|}{ Umur 40 tahun ke atas } & \multicolumn{2}{|c|}{ Umur 40 tahun ke bawah } \\
\hline & Ya & Tidak & Ya & Tidak \\
\hline Mudah memahami bahasa & 21 & 4 & 22 & 3 \\
\hline $\begin{array}{l}\text { halus walaupun tidak } \\
\text { menggunakan bahasa yang } \\
\text { berterus terang }\end{array}$ & $84 \%$ & $16 \%$ & $88 \%$ & $12 \%$ \\
\hline Selesa menggunakan & 24 & 1 & 22 & 3 \\
\hline $\begin{array}{l}\text { bahasa halus daripada } \\
\text { bahasa biasa/ bahasa kasar }\end{array}$ & $96 \%$ & $4 \%$ & $88 \%$ & $12 \%$ \\
\hline Menggunakan bahasa halus & 25 & 0 & 25 & 0 \\
\hline $\begin{array}{l}\text { sebagai cara menunjukkan } \\
\text { kesopanan }\end{array}$ & $100 \%$ & 0 & $100 \%$ & 0 \\
\hline
\end{tabular}

Menerusi data yang dipaparkan dalam Jadual 5 dan 6, dilihat bahawa peratusan penutur bagi kedua-dua kaum serta golongan umur yang memahami bahasa halus adalah tinggi. Walaupun bahasa halus tidak bersifat langsung, iaitu mengandungi kiasan atau wujud unsur metafora, didapati penutur mampu memahami perkataan dan ujaran bahasa halus yang digunakan disebabkan pemahaman mereka sejak sekian lama berkait dengan konteks penggunaannya. Fenomena ini mendorong penggunaan bahasa halus dalam komunikasi seharian dengan lebih banyak kerana keselesaan penutur menggunakan bahasa tersebut, di samping menunjukkan kesopanan dalam perbualan.

\section{Fungsi Penggunaan Bahasa Halus dalam Masyarakat Melayu Sarawak dan Iban}

Analisis dalam bahagian ini memaparkan fungsi penggunaan bahasa halus dalam konteks budaya dan hubungan antara penutur bahasa. Paparan data ditunjukkan melalui Jadual 7 dan Jadual 8:

Jadual 7

Fungsi penggunaan bahasa halus dalam masyarakat Melayu Sarawak

\begin{tabular}{|c|c|c|c|c|}
\hline & \multicolumn{2}{|c|}{ Umur 40 tahun ke atas } & \multicolumn{2}{|c|}{ Umur 40 tahun ke bawah } \\
\hline & Ya & Tidak & Ya & Tidak \\
\hline Penggunaan bahasa & 25 & 0 & 25 & 0 \\
\hline $\begin{array}{l}\text { halus dapat } \\
\text { menggambarkan budaya } \\
\text { dan identiti masyarakat }\end{array}$ & $100 \%$ & 0 & $100 \%$ & 0 \\
\hline Penggunaan bahasa & 25 & 0 & 22 & 3 \\
\hline $\begin{array}{l}\text { halus dapat merapatkan } \\
\text { hubungan antara } \\
\text { penutur sama bangsa }\end{array}$ & $100 \%$ & 0 & $88 \%$ & $12 \%$ \\
\hline
\end{tabular}


Jadual 8

Fungsi penggunaan bahasa halus dalam masyarakat Iban

\begin{tabular}{lcccc}
\hline & \multicolumn{2}{c}{$\begin{array}{c}\text { Umur } \mathbf{4 0} \text { tahun } \\
\text { ke atas }\end{array}$} & \multicolumn{2}{c}{$\begin{array}{c}\text { Umur } \mathbf{4 0} \text { tahun ke } \\
\text { bawah }\end{array}$} \\
\cline { 2 - 5 } & Ya & Tidak & Ya & Tidak \\
\hline Penggunaan bahasa halus dapat & 25 & 0 & 24 & 1 \\
$\begin{array}{l}\text { menggambarkan budaya dan identiti } \\
\text { masyarakat }\end{array}$ & $100 \%$ & 0 & $96 \%$ & $4 \%$ \\
\hline $\begin{array}{l}\text { Penggunaan bahasa halus dapat } \\
\text { merapatkan hubungan antara penutur }\end{array}$ & 24 & 1 & 25 & 0 \\
sama bangsa & $96 \%$ & $4 \%$ & $100 \%$ & 0 \\
\hline
\end{tabular}

Dapatan soal selidik daripada Jadual 7 dan Jadual 8 menunjukkan bahawa majoriti responden berpendapat bahawa, selain dapat merapatkan hubungan antara penutur sesama kaum, penggunaan bahasa halus turut menggambarkan budaya dan identiti masyarakat yang kaya dengan budi bahasanya. Hal ini dinyatakan demikian kerana sesuatu bahasa yang digunakan dalam masyarakat secara tidak langsung merupakan sebahagian daripada budaya kehidupan mereka, justeru dapat mencerminkan keperibadian sesebuah kaum, termasuklah kaum Melayu Sarawak dan Iban.

\section{Kesimpulan}

Dalam komunikasi, pemilihan dan penggunaan bahasa yang sesuai dapat menonjolkan kesantunan penutur, selain mampu mengeratkan hubungan, iaitu atas dasar saling menghormati dan bertimbang rasa dalam tutur kata. Dalam konteks Malaysia yang berbilang bangsa, kesantunan bukan sahaja wajar diterapkan dalam berbahasa, malah dalam bertingkah laku bagi menjaga keharmonian. Kajian yang dijalankan ini telah memperlihatkan bentuk bahasa halus yang digunakan dalam masyarakat Melayu Sarawak dan Iban, khususnya di kawasan Kuching dan Samarahan. Dapatan kajian juga menyumbang kepada pemahaman mengenai budaya berbahasa masyarakat Melayu Sarawak dan Iban khususnya dari aspek bahasa halus. Kajian-kajian yang melibatkan domain yang lain atau masyarakat lain di Sarawak wajar dilaksanakan untuk menunjukkan penggunaan bahasa ini secara lebih menyeluruh.

\section{Rujukan}

Affidah Morni, Aiza Johari, Johny Ahmad, \& Kamaruzaman Jusoff. (2009). The linguistic taboo between Malays and Ibans of Sarawak, Malaysia. Canadian Social Science, 5(3), 141-158.

Allan, K., \& Burridge, K. (1991). Euphemism \& dysphemism: Language used as shield and weapon. Oxford: Oxford University Press.

Asmah Haji Omar. (2008). Ensiklopedia Bahasa Melayu. Kuala Lumpur, Malaysia: Dewan Bahasa dan Pustaka. 
Hamidah Abdul Wahab, Imran Ho Abdullah, Mohammed Azlan Mis, \& Khazriyati Salehuddin. (2016). Analisis eufemisme kematian masyarakat Melayu Sarawak dari perspektif Semantik Kognitif. GEMA Online ${ }^{\circledR}$ Journal of Language Studies, 16(2), 53-71.

Jamet, D. (2018). The noelogical functions of disease euphemisms in English and French: Verbal hygiene or speech pathology? Journal in English Lexicology, 12, $1-26$.

Mohammed Azlan Mis. (2010). Lingua franca suku kaum di Sarawak. Jurnal Bahasa, 20, 131-151.

Mohammed Azlan Mis. (2012). Medium perantara pelbagai suku kaum di Sarawak: Kajian lingua franca. GEMA OnlineTM Journal of Language Studies, 12(3), 903922.

Noriah Mohamed, \& Jamilah Bebe Mohamad. (2016). Eufemisme leksikal dan metafora kematian dalam dialek Melayu Kedah. Journal of Education dan Social Sciences, 4, 331-342.

Rabab'ah, G., \& Al-Qarni, AM. (2012). Euphemism in Saudi Arabic and English. Journal of Pragmatics, 44, 730-743.

Radzi, H., \& David, P. (2012). Unsur eufemisme dan perumpamaan dalam teks hikayat Iban. Jurnal Linguistik, 16, 75-87.

Ringit, C., Hamidah Abdul Wahab \& Gedat, R. (2019). Domain kepercayaan bahasa halus masyarakat Iban Sebuyau, Sarawak: Analisis metafora konsepsi. Asian People Journal, 2(2), 18-30. 